\title{
Translocation of the cyanobacterial toxin microcystin-LR into guttation drops of Triticum aestivum and remaining toxicity
}

\section{Pflugmacher, Stephan}

2019-10

Pflugmacher , S, Sulk, A, Kim , S \& Esterhuizen-Londt, M 2019 , ' Translocation of the cyanobacterial toxin microcystin-LR into guttation drops of Triticum aestivum and remaining toxicity ' , Environmental Pollution , vol. 253 , pp. 61-67 . https://doi.org/10.1016/j.envpol.2019.07.027

http://hdl.handle.net/10138/332351

https://doi.org/10.1016/j.envpol.2019.07.027

cc_by_nc_nd

acceptedVersion

Downloaded from Helda, University of Helsinki institutional repository.

This is an electronic reprint of the original article.

This reprint may differ from the original in pagination and typographic detail.

Please cite the original version. 
1 Environmental Pollution: Full-length research paper

2 Translocation of the cyanobacterial toxin microcystin-LR into 3 guttation drops of Triticum aestivum and remaining toxicity Stephan Pflugmacher ${ }^{1,2,3,}$, Amalia Sulk ${ }^{1,2}$, Sanghun Kim4, Maranda Esterhuizen-

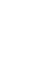

$$
\text { Londt }{ }^{1,2,3}
$$

$6 \quad{ }^{1)}$ University of Helsinki, Faculty of Biological and Environmental Sciences, Ecosystems

7 and Environment Research Programme, Aquatic Ecotoxicology in an Urban

8 Environment, Niemenkatu 73, 15140 Lahti, Finland

9 2) Joint Laboratory of Applied Ecotoxicology, Environmental Safety Group, Korea

10 Institute of Science and Technology Europe (KIST Europe) Forschungsgesellschaft

$11 \mathrm{mbH}$, Universität des Saarlandes Campus E7 1, Saarbrücken, 66123, Germany

${ }^{3)}$ Helsinki Institute of Sustainability (HELSUS), Fabianinkatu 33, 00014 Helsinki

13 4) Kyung-sung University, Department of Pharmaceutical Science and Technology, 191, 14 Jeongjail-ro, Bundang-gu, Seongnam-si, Gyeonggi-do, 13557 Republic of Korea

$16 *$ Corresponding author: Stephan Pflugmacher, University of Helsinki, Faculty of

17 Biological and Environmental Sciences, Ecosystems and Environment Research

18 Programme, Aquatic Ecotoxicology in an Urban Environment, Niemenkatu 73, 15140

19 Lahti, Finland, Tel: +35850 316 7329, Email: stephan.pflugmacher@,helsinki.fi 
- Microcystin-LR was taken up via the roots of Triticum aestivum.

- MC-LR could be detected in the roots, stems, and leaves.

- MC-LR occurred in xylem sap, and guttation drops at the same concentration.

- MC-LR was detected in and thus is transported via the xylem.

- MC-LR at the concentration occurring in the guttation drops is not toxic to daphids.

30 Microcystin was taken up by Triticum aestivum (wheat) after exposure via irrigation,

31 transported through the roots to the stems and leaves via the xylem, and could be

32 detected in the guttation drops. 
Uptake of the commonly occurring cyanobacterial toxin microcystin-LR (MC-LR) into crop plants via spray irrigation has been demonstrated. As other hazardous compounds such as pesticides were shown to be transported within plants, it was essential to understand the transport and fate of MC-LR in plants and the risks posed to grazers and other consumers. Of specific interest was to investigate if MC-LR could be detected in guttation drops and the toxicity thereof. Triticum aestivum (wheat) seedlings were exposed to $100 \mu \mathrm{g} \mathrm{L}^{-1} \mathrm{MC}-\mathrm{LR}$ in two separate experiments during which guttation drops were collected at various time points. The plants of one experiment were sectioned to investigate MC-LR distribution to the various plant appendages via liquid chromatography-tandem mass spectrometry analysis. After exposure, MC-LR could be detected in the roots, stems, leaves, and the guttation drops. However, the guttation drops were not toxic to Daphnia. As the environmentally relevant toxin concentration used was not sufficient to promote mortality in Daphnia, the physiological effect in insects, which rely on guttation drops as a water source, remains unknown. Combined with other contaminants that insects may be exposed to, the additional MC-LR exposure could contribute to the overall toxicity through the "tears of death".

51 Keywords: Cyanobacterial toxins, guttation, microcystin-LR, translocation, Triticum aestivum (wheat) 
Plants are the initiation point for most food webs, thus forming a central part of our global ecosystem. They are a vital resource of food for humans and animals, the latter in turn again serving as human food resources. For many years our ecosystems have had to face a constant input of ,xenobiotics“ (gr. xen(o) - strange; biosis - way of life), which are human-made compounds produced for a variety of purposes. Many of them are released deliberately, such as various pesticides in agricultural systems. The uptake of these organic pollutants into plants is usually a function of several chemical and physical properties they exhibit such as hydrophilicity, water solubility, and vapour pressure. The absorption depends on the respective pollutants and the environmental conditions such as temperature, UV-light, soil properties, plant species as well as plant health.

One of the critical factors for many physiological processes in plants is water. In plants, water is a solvent and a transport medium (for example for nutrients and photosynthetic products), is involved in numerous biochemical reactions and is responsible for turgor pressure and stomata opening. Therefore, after being taken up by millions of root hairs, which are thin-walled, slender extensions of the root epidermal cells, water moves freely from soil into the capillary spaces between the cortex in the roots. The water is then transported by a water gradient, with osmosis as the driving force. Once water is absorbed, there are two ways to move deeper into the plant, i.e. the apoplast pathway and symplast pathway (Hopkins, 1999). The apoplast pathway leads through the cell walls, which are freely permeable to small molecules. Through this pathway, the plant has no control over the movement of substances, as the cells are literally dead. However, 
substances including water have to enter the stele and thus xylem for transport through the symplast.

Plants cannot discriminate between beneficial or harmful compounds, nor can they distinguish between natural or xenobiotic substances. Unfortunately, most toxic compounds behave the same way as nutrients if the physicochemical properties are similar (Riederer, 1990). Transport within plants takes place in xylem and phloem. In mature plants, the tracheids in the xylem fibrous cells are dead, whereas in phloem sieve elements that have fully functional membranes are filled with living protoplasm. Movement in phloem is achieved by active processes, which generally require ATP (Trapp, 1995). Therefore, the transport of hydrophobic organic compounds is limited in the phloem.

Plants do have possibilities to excrete solutes. One of these possibilities is called guttation (lat. gutta = drop), which is the formation of drops exudated via xylem sap through hydathodes, a process linked to root pressure (Slayter, 1967) and is in some ways also derived from the transpiration stream (Fig. 1). As Klepper and Kaufmann (1966) discovered, guttation fluid and xylem sap have different chemical compositions, i.e. guttation fluid contains different kind of amino acids, sugars, and inorganic salts (Goatley and Lewis, 1966; Sheldrake and Northcote, 1968) and even some active enzymes can be detected in this fluid (Tab. 1) (Biles and Abeles, 1991; Kerstetter et al., 1998; Komarnytsky et al., 2000). In other words, the generation of the guttation fluid appears to be quite a selective process (Coupland and Caseley, 1979). In the past years, more and more reports have shown the presence of xenobiotics (Tab. 1), such as glyphosate, imidacloprid, or clothianidin in the guttation fluid (Girolami et al., 2009; Tapparo et al., 2011). The last two mentioned substances, belonging to the group of 
neonicotinoids, are hazardous for insects such as the honeybee (Ratnieks and Carrek, 2010).

104 Cyanobacterial blooms in freshwater bodies are a global environmental problem due to 105 promoted eutrophication and climate change (Scholz et al., 2017). As a result, the

106 occurrence of toxic cyanobacterial blooms as well as the amount of cyanobacterial

107 toxins, such as in the case of the hepatotoxic microcystins (Omidi et al., 2018), have

108 become considerably increased. These toxins may have interactions with central

109 components of aquatic ecosystems, i.e. aquatic plants causing adverse effects and 110 disrupting the ecosystem (Pflugmacher, 2004). As some of the bodies of water are used

111 for spray irrigation, cyanotoxins can be transferred into the food chain. The uptake of

112 cyanobacterial toxins has been documented in terrestrial plants (Pflugmacher et al.,

113 2006; Pflugmacher et al., 2007a and b; Contardo-Jara et al., 2018); however, its

114 excretion during plant guttation has not been investigated. Thus, it was necessary to

115 investigate the fate and transport of a commonly occurring cyanobacterial toxin in a

116 terrestrial plant. As microcystin-LR (MC-LR) is so commonly detected and well studied

117 (Omidi et al., 2018), it was chosen for this investigation. The present study, therefore,

118 aimed to investigate the plant internal transport of the cyanobacterial toxin MC-LR after

119 uptake via the root system. Furthermore, the possibility of MC-LR transfer into guttation

120 drops was investigated. Guttation drops are an important water source for many insects,

121 especially bees, and could negatively affect biodiversity indirectly. Therefore, the

122 potential toxicity of the guttation drops was tested using the immobilisation test of the

123 crustacea Daphnia magna as a sentinel for hazards stemming from guttation drops. 
All chemicals were analytical grade and purchased from Sigma Aldrich unless stated otherwise. MC-LR (HPLC-grade; purity $\geq 95 \%$ ) isolated from Microcystis aeruginosa was obtained from Enzo Life Sciences (Germany). The toxin was suspended and diluted with HPLC-grade methanol (VWR International GmbH, France) to an MC-LR stock solution of $100 \mu \mathrm{g} \mathrm{L}^{-1}$ before storage at $-20^{\circ} \mathrm{C}$.

\subsection{Wheat plant cultivation}

132 reagent tubes filled two thirds with washed, sterilised $\left(20 \mathrm{~min}, 121^{\circ} \mathrm{C}\right)$ sand in semi-

144 hydroponic culture using the standard medium. Seeds were placed $0.5-1.0 \mathrm{~cm}$ deep 145 into the sand for further growth and incubated at $25^{\circ} \mathrm{C}$ with a day/night cycle of $14 \mathrm{~h}: 10$ 
$\mathrm{h}\left(100 \mu \mathrm{E} \mathrm{m}^{-2} \mathrm{~s}^{-1}\right)$ in a commercially available greenhouse $\left(4.6 \mathrm{~m}^{2}\right.$ size, Bauhaus, Berlin,

147 Germany) made of polycarbonate plates and aluminium frame.

\subsection{Collection of guttation liquid}

149 To initiate guttation of the seedlings, the reagent tubes were placed in trays with water to

150 maintain a high humidity of $95 \%$. When the seedling shoots were up to $3 \mathrm{~cm}$ tall after 6

$151 \mathrm{~d}$, guttation liquid was collected twice daily for the following $3 \mathrm{~d}$, drop by drop from the

152 hydathodes around of the primary leaf using a glass Pasteur pipette before the exposures

153 commenced. Droplets had an average size $1.35 \pm 0.14 \mathrm{~mm}(n=800)$ and the average

154 volume per wheat hydathode per night was $0.8 \pm 0.3 \times 10^{-7} \mathrm{~L}$. After sampling the

155 guttation drops collected were immediately frozen in liquid nitrogen and stored at -

$15680^{\circ} \mathrm{C}$. Guttation liquid exhibit a $\mathrm{pH}$ of $5.1 \pm 0.1$.

\subsubsection{Transfer of toxin into plant sections}

159 After $6 \mathrm{~d}$ of growth, a total of 1000 seedlings, separated in five independent batches

160 with 200 seedlings each, were obtained. These batches were again separated into five

161 independent batches with 25 seedlings each. Each seedling was irrigated daily for $7 \mathrm{~d}$

162 with water $(1000 \mu \mathrm{L}$ per seedling $)$ containing $100 \mu \mathrm{g} \mathrm{L}^{-1} \mathrm{MC}-\mathrm{LR}(0.7 \mu \mathrm{g}$ MC-LR per

163 seedling). As an independent control, 100 seedlings were irrigated with water without

164 toxin. The seedlings were collected after 0 h, 2 h, 4 h, 24 h, 48 h, 72 h, 96 h, 120 h, 144

$165 \mathrm{~h}$, and $168 \mathrm{~h}$. The seedlings were washed with methanol and water in three successions

166 to remove any possible surface bound MC-LR on the roots and then separated into root,

167 stem, and leaf sections. Guttation drops were sampled twice a day using glass Pasteur

168 pipettes for $7 \mathrm{~d}$. Guttation drop samples were combined from each batch from exposure 
as well as the controls separately for liquid chromatography-tandem mass spectrometry (LC-MS/MS) analysis (described in section 2.5).

\subsubsection{Toxin content in guttation drops and xylem sap}

172 After $6 \mathrm{~d}$ of growth, a total of 500 seedlings (divided into 5 batches) were each exposed

173 to $1000 \mu \mathrm{L}$ of water containing $100 \mu \mathrm{g} \mathrm{L}-1$ MC-LR $(0.1 \mu \mathrm{g})$ for $96 \mathrm{~h}$ and $168 \mathrm{~h}$

174 respectively before sampling. As a control, 100 seedlings in total were irrigated with

175 water without toxin. For xylem sap sampling, the seedlings were cut $1.0 \mathrm{~cm}$ above the

176 sand surface using a sharp scalpel to collect xylem sap coming from the root system

177 directly. Xylem sap was collected using a glass Pasteur pipette and combined from all

178 seedlings of one batch in exposure as well as control samples, separately.

\subsubsection{Toxicity of guttation drops}

180 In order to investigate the potential toxicity of the guttation drops, the Daphnia sp. acute 181 immobilisation test according to ISO 6341:2012 (2012) was performed. Daphnia magna

182 Strauss from an established laboratory culture was used. To set up the test, young $D$.

183 magna aged less than $24 \mathrm{~h}$ were exposed to the guttation drops in various concentrations

184 for a period of $48 \mathrm{~h}$. The immobilisation was recorded after $48 \mathrm{~h}$ and compared with

185 control values. The dilutions were prepared in standard water $\left(294 \mathrm{mg} \cdot \mathrm{L}^{-1} \mathrm{CaCl}_{2} \cdot \mathrm{H}_{2} \mathrm{O}\right.$,

$186123 \mathrm{mg} \cdot \mathrm{L}^{-1} \mathrm{MgSO}_{4} \cdot 7 \mathrm{H}_{2} \mathrm{O}, 63.0 \mathrm{mg} \cdot \mathrm{L}^{-1} \mathrm{NaHCO}_{3}$, and $5.50 \mathrm{mg} \cdot \mathrm{L}^{-1} \mathrm{KCl}$ ) at a $\mathrm{pH}$ of 7.0 .

187 For each concentration tested, in total 20 animals were divided into four groups, i.e. five

188 animals were used per treatment replicate, the control and positive control. The exposure 189 temperature was $19 \pm 1^{\circ} \mathrm{C}$ and a $16 \mathrm{~h}: 8 \mathrm{~h}$ light/dark cycle was applied. Test vessels were

190 not aerated during the test, nor was any food supplied to the D. magna during the test. 
193 To reach detectable MC-LR concentrations for toxin analysis via LC-MS/MS, a pre-

194 concentration of MC-LR via solid-phase-extraction (SPE) was done using reversed195 phase cartridges (Sep-Pak ${ }^{\circledR}$ tC18, 400 mg sorbent, Waters, Ireland). The sample was 196 passed through the SPE tube for toxin enrichment followed by eluting with $5 \mathrm{~mL}$ of 197 99\% methanol (Carl Roth, Germany). Subsequently, all methanol was removed in a 198 vacuum centrifuge (Concentrator plus/Vacufuge ${ }^{\circledR}$ plus, Eppendorf AG, Germany) at a 199 temperature of $30^{\circ} \mathrm{C}$ and finally resuspended in $500 \mu \mathrm{L}$ HPLC-grade methanol 200 (Spengler et al., 2015). MC-LR quantification was performed by LC-MS/MS (Alliance 2695 UHPLC combined with a Micromass Quattro microTM, Waters) using the reverse phase column Kinetex ${ }^{\mathrm{TM}}$ C18 (2.1 mm $\times 50 \mathrm{~mm}, 2.6 \mu \mathrm{m}$ pore size, Phenomenex, USA). The column oven 204 temperature was set at $40^{\circ} \mathrm{C}$ with an injection volume of $20 \mu \mathrm{L}$. The mobile phase 205 consisted of solution A (Milli-Q water containing $0.1 \%$ trifluoroacetic acid (TFA) and 206 $5 \%$ acetonitrile $(\mathrm{ACN})$ ) and solution $\mathrm{B}(\mathrm{ACN}$ containing $0.1 \% \mathrm{TFA})$ at a flow rate of

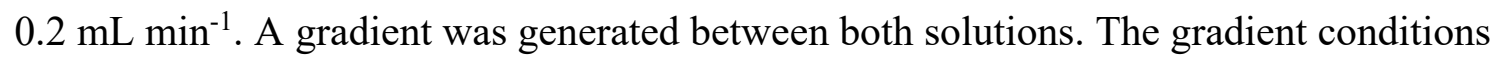
208 (solution A: solution B) were 65:35 at $3 \mathrm{~min}, 35: 65$ from 3.75 to $7 \mathrm{~min}$ and 0:100 from 2097.8 to $12 \mathrm{~min}$. An elution peak for MC-LR was observed at $7.44 \mathrm{~min}$. Mass spectral data 210 analyses were performed using electrospray ionisation (ESI) in a positive ion mode with 211 a collision energy of $65 \mathrm{~V}$. Desolvation gas $\mathrm{N}_{2}$ was set as trigger gas and argon as the 212 collision gas. For the subsequent MS/MS detection, the MRM mode was used with a 213 mass transfer of 995.5 (Q1) and 107.3, 135.1, 213.2 and 357.2 (Q3) for MC-LR.

214 Calibration was linear $\left(r^{2}=0.999\right)$ between 5 and $500 \mu \mathrm{g} \mathrm{L}^{-1}$. The LOD was $1 \mu \mathrm{g} \mathrm{L}^{-1}$, 215 and LOQ was $2 \mu \mathrm{g} \mathrm{L}^{-1}$ (Contardo-Jara et al., 2015). 
218

SPSS was used to perform a descriptive analysis based on the mean of toxin content (Arbuckle, 2010). Results are expressed as mean \pm standard deviation (SD). Data were submitted to one-way analysis of variance (ANOVA). When the overall F statistic was significant, pair-wise comparisons were performed by Tukey-Kramer test (Sokal and Rohlf, 1997). An alpha value of 0.05 level was set for significance.

\section{Results and Discussion}

Exposure of agricultural plants via spray irrigation to water containing cyanobacterial toxins have severe effects on plant physiology and therefore also have economic consequences (Codd et al., 1999; McElhiney et al., 2001). Accumulation of cyanotoxins in plants via spray irrigation as the source has been reported previously (Pflugmacher et al., 2007a and b; Peuthert et al., 2007; Lahrouni et al., 2015; Contardo-Jara et al., 2018).

However, the fate of these toxins within the plant remains poorly understood. As seen for Phragmites australis, the MC-LR is taken up by plant root systems and internally transported into stem and leaves (Pflugmacher et al., 2001). Based on this result, longdistance transport of the polar molecule MC-LR via the xylem becomes a plausible scenario and was thus investigated. For the pesticide imidacloprid, an acropetal xylem transport was shown in Citrus sinensis, after application of the pesticide to the tree bark (Mendel et al., 2000). According to Rudolph-Böhmer et al. (1994), MC-LR contains two ionizable carboxyl groups and one ionizable amino group outside the cyclic structure formed by peptide bonds. The pKa values of those groups ranged between 2.09 and 12.48 (Rudolph-Böhner et al., 1994). The pKa is one determinant for the ability to 
penetrate biomembranes and responsibility for root uptake and translocation into the

241 xylem of a molecule (Sur and Stork, 2003).

\subsection{Transfer of toxin into plant sections}

243 In the present study, exposure of the seedlings to MC-LR led to an uptake of the toxin 244 into the plant (Fig. 2). As the only parts exposed to MC-LR, uptake occurred via the root 245 pathway. Uptake was time-dependent, starting with the detection of $1.4 \pm 0.3 \mu \mathrm{g} \mathrm{g}^{-1} \mathrm{MC}^{-}$ 246 LR in the roots as soon as $2 \mathrm{~h}$ after exposure commenced, increasing exponentially $\left(r^{2}=\right.$ 2470.976 ) to a maximum concentration of $69.6 \pm 7.4 \mu \mathrm{g} \mathrm{g}^{-1}$ after $168 \mathrm{~h}$ (Fig. 2A). As MC-

248 LR is a water-soluble polar compound, it can be assumed it entered the root dissolved in 249 water via the apoplastic pathway. However, it is likely that the hydrophobicity of the 250 Casparian stripe forced the dissolved MC-LR to transverse the plasma membrane to 251 enter the symplast where it likely entered, according to its chemical properties, the 252 xylem as it was detected in the stems (Fig 2B).

253 During the exposure period, the toxin moves through the stem (max. concentration after $254168 \mathrm{~h} 40.9 \pm 2.8 \mu \mathrm{g} \mathrm{g}^{-1}$ ) (Fig. 2B) into the leaves of the seedlings (max. concentration of 255 toxin after $168 \mathrm{~h} 55.6 \pm 6.6 \mu \mathrm{g} \mathrm{g}^{-1}$ ) (Fig. 2C). Detecting MC-LR in the leaves of plants 256 of which only the roots were exposed to MC-LR, supports the hypothesis that MC-LR is 257 transported via the xylem. No toxin could be detected in the control plants that were 258 watered only with toxin-free water.

260 In a semi-field experiment using T. aestivum exposed to MC-LR and -RR as well as a

261 cell-free cyanobacterial crude extract individually for three months $\left(0.5 \mu \mathrm{g} \mathrm{L}^{-1}\right)$, the 262 effects on root growth could be clearly shown (Pflugmacher et al., 2007b). However, in 263 the current study during which a substantially lower exposure concentration was used 
$264\left(100 \mu \mathrm{g} \mathrm{L}^{-1}\right)$ for a shorter period $(7 \mathrm{~d})$, no adverse effects on root growth could be 265 observed.

267 In the guttation drops, MC-LR could already be detected after $48 \mathrm{~h}$ at a concentration of $2684.6 \pm 1.6 \mathrm{mg} \mathrm{L}^{-1}$ (Fig. 3). The toxin concentration in the guttation drops increased exponentially with time $\left(\mathrm{r}^{2}=0.979\right)$ to $60.0 \pm 2.8 \mathrm{mg} \mathrm{L}^{-1}$ after $168 \mathrm{~h}$ of exposure. The

270 detection of MC-LR in the guttation drops indicate an active transport of the toxin via 271 the stems into the leaves and the guttation drops. When calculating the amount of MC272 LR detected in the guttation liquid per seedling after $7 \mathrm{~d}$, a total of $2.4 \mu \mathrm{g}$ per seedling was reached. A similar calculation by Riebe (2009) showed that the amount of neonicotinoids in the guttation liquid per seedling was in the range of $0.5-1.3 \mathrm{mg}$. Those values refer to a whole growing season and not only to a $7 \mathrm{~d}$ growth experiment. Taking into account the effect of pooling all the guttation drops from the leaves of $T$. aestivum seedlings; this also may have led to a kind of dilution.

\subsection{Toxin content in guttation drops and xylem sap}

When comparing the toxin concentration of the xylem sap and guttation drop (Fig. 4), the transport is manifested. Guttation drops are exudates of the xylem sap. At night, stomata of plants are usually closed. Therefore no transpiration occurs. Root pressure builds up because water from soil moisture will force water to enter the roots. This root pressure forces water to exude through the hydathodes, forming guttation drops (Wilson, 1923). After $96 \mathrm{~h}$ of exposure, $19.3 \pm 6.9 \mathrm{mg} \mathrm{L}^{-1} \mathrm{MC}-\mathrm{LR}$ could be measured in the xylem sap samples (Fig. 4). The toxin concentration in the guttation drops at the same time was $11.6 \pm 2.2 \mathrm{mg} \mathrm{L}^{-1}$, resembling $60 \%$ of the xylem sap concentration. After 168 $\mathrm{h}$ of exposure, the MC-LR concentration in xylem sap reached $56.6 \pm 9.1 \mathrm{mg} \mathrm{L}^{-1}$, and 
the concentration in the guttation drops reached $52.4 \pm 7.2 \mathrm{mg} \mathrm{L}^{-1}$. Typically, the dissolved content of salts, sugars, amino acids, or even whole enzymes (catalase, peroxidase) in the guttation drops (Wilson, 1923; Biles and Abeles, 1991) is very low and usually below 1\% (Pistorius et al., 2011). The amount of MC-LR detected in the guttation drop after $168 \mathrm{~h}$ exposure was $0.024 \%$ of the total applied toxin amount of 100 $\mu g \mathrm{~L}^{-1}$.

295 Comparing the molecular sizes of compounds such as galactose $\left(180.16 \mathrm{~g} \mathrm{~mol}^{-1}\right)$, 296 inositol $\left(180.16 \mathrm{~g} \mathrm{~mol}^{-1}\right)$, asparagine $\left(132.12 \mathrm{~g} \mathrm{~mol}^{-1}\right)$, glutamine $\left(146.14 \mathrm{~g} \mathrm{~mol}^{-1}\right)$, and 297 methionine $\left(149.21 \mathrm{~g} \mathrm{~mol}^{-1}\right)($ Goatly and Lewis, 1966) or some pesticides such as 298 clothianidin $\left(249.68 \mathrm{~g} \mathrm{~mol}^{-1}\right)$, diuron $\left(233.10 \mathrm{~g} \mathrm{~mol}^{-1}\right)$ or chloramben $\left(206.02 \mathrm{~g} \mathrm{~mol}^{-1}\right)$ 299 (Stroller, 1970), previously detected in guttation drops, MC-LR (995.16 $\left.\mathrm{g} \mathrm{mol}^{-1}\right)$ is 300 significantly larger. However, as even larger biomolecules such as the enzymes catalase $301\left(240,000 \mathrm{~g} \mathrm{~mol}^{-1}\right)$ or peroxidases $\left(44,000 \mathrm{~g} \mathrm{~mol}^{-1}\right)$ are secreted into guttation drops, the 302 hepatotoxin is within the lower range. However, these enzymes are synthesised within the plant cell, and MC-LR is taken up via the root from outside. This means that the toxin has to overcome the Casparian strip barrier in order to enter the xylem sap. As MC-LR could be detected in roots, stem, and leaf, the uptake mechanisms (transporters) might be similar to amino acid and protein taken up into root cells (Lonhienne et al., 2014). MC-LR consists of a ring of seven amino acids, so it can be speculated that similar transporters are involved such as proton-amino acid symporters (Eriksson et al., 1990). In addition, the uptake of MC-LR via pinocytic processes has been discussed as a

310 possible uptake route (Vesterkvist and Meriluoto, 2003).

311 According to Ortiz-Lopez et al. (2000), more than two dozen amino acid transporters in 312 plants are known, some of which might be active in bringing MC-LR into the root cells. 
The concentration of toxin in the guttation drops was visually but not statistically lower

314 than that detected on xylem sap after both 96 and $168 \mathrm{~h}$ of exposure $(p>0.05)$;

315 nevertheless, the small difference indicated the removal of the toxin from the xylem sap

316 during the movement through the epithelium. This removal might be due to possible

317 biotransformation via conjugation by glutathione S-transferases as seen already in

318 different plants (Pflugmacher et al., 1998; 2001).

\subsection{Toxicity of guttation drops}

Detection of MC-LR in the guttation drops led to the question of whether this poses any

321 risk to insects using guttation drops as a water source. Guttation drops are for many insects, including honeybees (Riebe, 2009), a potential source of water, even though this source is available the whole day, but only in the morning and evenings, and even not daily. Honeybees usually need water in the hive to regulate air humidity, to cool down the temperature, and for the production of larval food (Johansson and Johansson, 1978); however, there is no water storage in the hive. As the water collecting worker bees might choose water sources near (around $50 \mathrm{~m}$ ) the hive to avoid energy consuming long-distance flights, an agricultural field nearby might present as the closest water source (Kuehnholz and Seeley, 1997; Shawki et al., 2006).

To test the potential toxicity of guttation drops, the well-established ecotoxicological 331 test using D. magna immobilisation was performed. LC50 was calculated according to 332 Finney (1952) to be $1.48 \pm 0.29 \mathrm{mg} \mathrm{L}^{-1}$ for the guttation drops. For MC-LR, the $48 \mathrm{~h}$

333 LC50 reported in literature ranged from 1.78 to $6.86 \mathrm{mg} \mathrm{L}^{-1}$ (Sieroslawska, 2013; Piontek 334 and Czyzewska, 2017). Therefore, the toxicity of MC-LR secreted into the guttation 335 drops is still on the lower range of pure MC-LR tested. MC-LR was reported to be toxic 336 to terrestrial insects such as Plutella xylostella (diamond-backed moth), Spodoptera 337 littoralis (cotton leafworm), Pieris brassicae (cabbage white butterfly), and Musca 
domestica (housefly). For P. xylostella, an $\mathrm{LC}_{50} 24 \mathrm{~h}$ of $1.02 \mu \mathrm{g}$ toxin per $\mathrm{cm}^{2}$ treated

339 leaf surface was detected (Delaney and Wilkins, 1995). Other insects such as

340 Periplaneta americana (American cockroach), Tenebrio molitar (Yellow mealworm),

341 and Gryllus bimaculatus bimaculatus (common cricket) showed greater sensitivity

342 towards MC-LR, which is toxic to them (Oberholster et al., 2009). However, further,

343 more thorough toxicological testing of the guttation drops is necessary to evaluate any

344 threats posed to insects.

\section{Conclusion}

347 After exposure, MC-LR could be detected in all three tested plant sections of $T$.

348 aestivum seedlings and the guttation drops. As the environmentally relevant

349 concentration of the toxin used in the present experiment was not sufficient to promote

350 mortality in D. magna, it is still unknown how insects which rely on guttation drops as a

351 source of water will react physiologically in nature. Combined with other contaminants

352 that insects may be exposed to, this route of MC-LR exposure contributes to the overall

353 toxicity through the guttation as the plant "tears of death". 
355 SP, AS, SK and MEL designed the research; SP, AS performed the research; SP

356 analysed the data, and SP and MEL wrote the paper. All authors read, gave comments,

357 and approved the manuscript.

358

359

\section{Funding}

360 This research did not receive any specific grant from funding agencies in the public,

361 commercial, or not-for-profit sectors.

362

363

Declaration of interest

364 The authors declare that there is no conflict of interest.

365

366

ORCID

367 Stephan Pflugmacher: https://orcid.org/0000-0003-1052-2905

368 Amalia Sulk: N/A

369 Sanghun Kim: https://orcid.org/0000-0002-2936-5084

370 Maranda Esterhuizen-Londt: https://orcid.org/0000-0002-2342-3941 
372 Arbuckle, J.L., 2010, IBM SPSS 19 Users guide. Amos Development Corporation,

373 Crawfordville.

374 Biles, C.L., Abeles, F.B., 1991. Xylem sap proteins. Plant Physiol. 96, 597-601.

375 Chang, R., 1981. Physical chemistry with applications to biological systems. MacMillan 376 Publishing Co. Inc, New York.

377 Codd, G.A., Metcalf, J.S., Beattie, K.A., 1999. Retention of Microcystis aeruginosa and 378 microcystin by salad lettuce (Lactuca sativa) after spray irrigation with water containing 379 cyanobacteria, Toxicon $37,1181-1185$.

380 Contardo-Jara, V., Schwanemann, T., Esterhuizen-Londt, M., Pflugmacher, S., 2018.

381 Protein association of $\beta$-N-methylamino-L-alanine in Triticum aestivum via irrigation.

382 Food Addit. Contam. Part A 35, 731-739.

383 Contardo-Jara, V., Kuehn, S., Pflugmacher, S., 2015. Single and combined exposure to 384 MC-LR and BMAA confirm suitability of Aegagropila linnaei for use in green liver 385 systems - a case study with cyanobacterial toxins. Aquat. Toxicol. 165, 101-108.

386 Coupland, D., Caseley, J.C., 1979. Presence of ${ }^{14} \mathrm{C}$ activity in root exudates and 387 guttation fluid from Agropyron repens treated with ${ }^{14} \mathrm{C}$-labelled glyphosate. New Phytol. $388 \quad 83,17-22$

389 Delaney, J.M., Wilkins, R.M., 1995. Toxicity of microcystin-LR isolated from 390 Microcystis aeruginosa against various insect species. Toxicon 33, 771-778. 
Eriksson, J.E., Grönberg, L., Nygard, S., Slotte, J.P., Meriluoto, J.A.O., 1990.

392 Hepatocellular uptake of ${ }^{3} \mathrm{H}$-dihydromicrocystin- LR, a cyclic peptide toxin. Biochim. 393 Biophys. Acta 1025, 60-66.

394 Finney, D.J., 1952. On the precision of biological assays. Acta Pharmacol. Toxicol. 8, $395 \quad 55-70$.

396 Frommberger, M., Pistorius, J., Schier, A., Joachimsmeier, I., Schenke, D., 2011.

397 Guttation and the risk for honey bee colonies (Apis mellifera L.): a worst case semi-field 398 scenario in maize with special consideration of impact on bee brood and brood 399 development. $11^{\text {th }}$ International symposium of the ICP-BR Bee Protection group 400 (ICPBR), Wageningen, Netherlands. DOI: 10.5073/jka.2012.437.015

401 Girolami, V., Mazzon, L., Squartini, A., Mori, N., Marzaro, M., Di Bernardo, A., 402 Greatti, M., Giorio, C., Tapparo, A., 2009. Translocation of neonicotinoid insecticides 403 from coated seeds to seedlings guttation drops: A novel way of intoxication for bees. J. 404 Econ. Entomol. 102, 1808-1815.

405 Goatley, J.L., Lewis, R.W., 1966. Composition of guttation fluid from rye, wheat, and 406 barley seedlings. Plant Physiol. 41, 373-375.

407 Hoffmann, E.J., Castle, S.J., 2012. Imidacloprid in melon guttation fluid: a potential 408 mode of exposure for pest and beneficial organisms. J. Econ. Entomol. 105, 67-71.

409 Hopkins, W.G., 1999. The physiology of plants under stress, in: Hopkins, W., Huener, 410 N.P.A. (Eds.), Introduction to plant physiology $2^{\text {nd }}$ edn, John Wiley \& Sons, Inc., New 411 York, pp. 451-475. 
412 ISO 6341:2012. Water Quality - Determination of the inhibition of the mobility of

413 Daphnia magna Strauss (Cladocera, Crustacea) - Acute toxicity test. Fourth edition,

414 International Organization for Standardization, Geneva, Switzerland.

415 Johansson, T.S.K., Johansson, M.P., 1978. Providing honeybees with water, Bee World $41659,11-17$.

417 Kerstetter, R.E., Zepp, R.G., Carreira, L.H., 1998. Peroxidases in grass dew from 418 guttation: possible role in polymerization of soil organic matter. Biogeochemistry 42, $419 \quad 311-323$.

420 Klepper, B., Kaufmann, M.R., 1966. Removal of salt from the xylem sap by leaves and 421 stem of guttating plants. Plant Physiol. 41, 1743-1747.

422 Komarnytsky, S., Borisjuk, N.V., Borisjuk, L.G., Alam, M.Z., Raskin, I., 2000.

423 Production of recombinant proteins in tobacco guttation fluids. Plant Physiol. 124, 927424933.

425 Kuehnholz, S., Seeley, T.D., 1997. The control of water collection in honey bee 426 colonies. Behav. Ecol. Sociobiol. 41, 407-422.

427 Lahrouni, M., Oufdou, K., El Khalloufi, F., Pajuelo, E., 2016. Microcystin-tolerant 428 Rhizobium protects plants and improves nitrogen assimilation in Vicia faba irrigated 429 with microcystin-containing waters. Environ. Sci. Pollut. Res. 23, 10037-10049.

430 Larson, J.L., Redmond, C.T., Potter, D.A., 2015. Mowing mitigates bioactivity of 431 neonicotinoid insecticides in nectar of flowering lawn weeds and turfgrass guttation. 432 Environ. Toxicol. Chem. 34, 127-132. 
433

434

435

436

437

438

439

440

441

442

443

444

445

446

447

448

449

450

451

452

453

454

Lonhienne, T.G.A., Trusov, Y., Young, A., Rentsch, D., Näsholm, T., Schmidt, S., Paungfoo-Lonhienne, C., 2014. Effects of externally supplied protein on root morphology and biomass allocation in Arabidopsis. Sci. Rep. 4, 5005.

McElhiney, J., Lawton, L.A., Leifert, C., 2001. Investigations into the inhibitory effects of microcystins on plant growth, and the toxicity of plant tissues following exposure. Toxicon 39, 1411-1420.

Mendel, R.M., Reckmann, U., Führ, F., 2000. Xylem transport of the pesticide imidacloprid in Citrus. ISHS Acta Horticulture 531, 129-134. DOI:

10.17660/ActaHortic.2000.531.18

Oberholster, P.J., Mthethwa, B.L.S., Botha, A.M., 2009. Development of a rapid and sensitive battery of bioassays for risk assessment of cyanobacterial microcystin-LR in drinking water of rural water treatment plants, South Africa. Afr. J. Biotechnol. 8, 45624571.

Omidi, A., Esterhuizen-Londt, M., Pflugmacher, S., 2018. Still challenging: The ecological function of the cyanobacterial toxin microcystin-What we know so far. Toxin Rev. 37, 87-105.

Ortiz-Lopez, A., Chang, H.C., Bush, D.R., 2000. Amino acid transporters in plants. Biochim. Biophys. Acta 1465, 275-280.

Peuthert, A., Chakrabarti, S., Pflugmacher, S., 2007. Uptake of microcystins-LR and LF (cyanobacterial toxins) in seedlings of several important agricultural plant species and the correlation with cellular damage (lipid peroxidation). Environ. Toxicol. 22, 436442. 
Pflugmacher, S., 2004. Promotion of oxidative stress in the aquatic macrophyte

Ceratophyllum demersum during biotransformation of cyanobacterial toxin microcystinLR. Aquat. Toxicol. 70, 169-178.

Pflugmacher, S., Aulhorn, M., Grimm, B., 2007. Influence of a cyanobacterial crude extract containing microcystin-LR on the physiology and antioxidative defence systems of different spinach variants. New Phytol. 175, 482-489.

Pflugmacher, S., Hoffmann, J., Hübner, B., 2007. Effects on growth and physiological parameters in wheat (Triticum aestivum L.) grown in soil and irrigated with cyanobacterial toxin contaminated water. Environ. Toxicol. Chem. 26, 2710-2716.

Pflugmacher, S., Jung, K., Lundvall, L., Neumann, S., Peuthert, A., 2006. Effects of cyanobacterial toxins and cyanobacterial cell-free crude extract on germination of alfalfa (Medicago sativa) and induction of oxidative stress. Environ. Toxicol. Chem. 25, 23812387.

Pflugmacher, S., Wiegand, C., Oberemm, A., Beattie, K.A., Krause, E., Codd, G.A., Steinberg, C.E.W., 1998. Identification of an enzymatically formed glutathione conjugate of the cyanobacterial hepatotoxin microcystin-LR: the first step of detoxication. Biochim. Biophys. Acta 27, 527-533.

Pflugmacher, S., Wiegand, C., Beattie, K.A., Krause, E., Steinberg, C.E.W. Codd, G.A., 2001. Uptake, effects and metabolism of cyanobacterial toxins in the emergent reed plant Phragmites australis (cav.) trin. ex steud. Environ. Toxicol. Chem. 20, 846-852.

Piontek, M., Czyzewska, W., 2017. Influence of cyanobacterial bloom on freshwater biocoenosis. Use of Bioassays for cyanobacterial microcystins toxicity assessment. Civil Environ. Eng. Rep. 24, 47-68. 
Pistorius, J., Brobyn, T., Campbell, P., Forster, R., Lortsch, J.-A., Marolleau, F., Maus, C., Lückmann, J., Suzuki, H., Wallner K., et al., 2011. Assessment of risks to honey bees posed by guttation. $11^{\text {th }}$ International Symposium of the ICP-BR Bee Protection Group (ICPBR), Wageningen, Netherlands. DOI: 10.5073/jka.2012.437.056

Ratnieks, F.L.W., Carreck, N.L., 2010. Clarity on honey bee collapse? Science 327, 152-153.

Riebe, E., 2009.Exposition Paths of Neonicotinoids. DBIB, Paris.

http://www.bitsandbees.n1/Expo-Paths-Paris.pdf.

Riederer, M., 1990. Estimating partitioning and transport of organic chemicals in the foliage/atmosphere systems: discussion of a fugacity-based model. Environ. Sci. Technol. 24, 829-837.

Rudolph-Böhner, S., Mierke, D.F., Moroder, L., 1994. Molecular structure of the cyanobacterial tumor-promoting microcystin. FEBS Letters 349, 319-323.

Scholz, S.N., Esterhuizen-Londt, M., Pflugmacher, S., 2017. Rise of toxic cyanobacterial blooms in temperate freshwater lakes: Causes, correlations and possible countermeasures. Toxicol. Environ. Chem. 99, 543-577.

Shawki, M.A.A., Titera, D., Kazda, J., Kohoutkova, J., Taborsky, V., 2006. Toxicity to honeybees of water guttation and dew collected from winter rape treated with Nurelle $\mathrm{D}^{\circledR}$. Plant Prot. Sci. 42, 9-14.

Sheldrake, A.R., Northcote, D.H., 1968. Some constituents of xylem sap and their possible relationship to xylem differentiation. J. Exp. Bot. 19, 681-689. 
Sieroslawska, A., 2013. Evaluation of the sensitivity of organisms used in commercially available tox-kits to selected cyanotoxins. Pol. J. Environ. Stud. 22, 1817-1823.

Slayter, R.O., 1967. Plant-water relationships, Academic Press, New York.

Sokal, R.R., Rohlf, F.J., 1997. Biometry: The principles and practice of statistics in biological research. WH Freeman and Company, New York.

Spengler, A., Contardo-Jara, V., Pflugmacher, S., 2015. Potential role of engineered nanoparticles as contaminant carriers in aquatic ecosystems: Estimating sorption processes of the cyanobacterial toxin microcystin-LR by $\mathrm{TiO}_{2}$ nanoparticles. Colloids Surf. A 481, 460-467.

Stevens, A.B.P., 1956. The structure and development of the hydathodes of Caltha palustris L. New Phytol. 55, 339-345.Stoller, E.W., 1970. Mechanism for the differential translocation of amiben in plants. Plant Physiol. 46, 732-737.

Sur, R., Stork, A., 2003. Uptake, translocation and metabolism of imidacloprid in plants. B. Insectol. 56, 35-40.

Tapparo, A., Giorio, C., Marzaro, M., Marton, D., Sold, L., Girolami, V., 2011. Rapid analysis of neonicotinoid insecticides in guttation drops of corn seedlings obtained from coated seeds. J. Environ. Monit. 13, 1564-1568.

Trapp, S., 1995. Model for uptake of xenobiotics into plants, in: Trapp, S., McFarlane, J.C. (Eds.), Plant Contamination: modelling and simulation of organic chemical processes, CRC Press, Boca Raton, pp. 107-150.

Vesterkvist, P.S.M., Meriluoto, J.A.O., 2003. Interactions between microcystins of different hydrophobicities and lipid monolayers. Toxicon 41, 349-355. 
521 Walters, D.R., Kingham, G., 1990. Biosynthesis inhibitors by barley seedlings: Effects 522 of mildew infections. New Phytol. 114, 659-665.

523 Wilson, J.K., 1923. The nature and reaction of water from hydathodes. Cornell 524 Agricultural Experiment Station Memoir 65, 3-11. 
525 Table 1: Different compounds previously detected in guttation drops of different plants.

526 For pesticides, the concentrations were in the $\mathrm{mg} \mathrm{L}^{-1}$ range for a more extended vegetation

527 period.

\begin{tabular}{|c|c|c|c|}
\hline $\begin{array}{c}\text { Compound/protei } \\
n\end{array}$ & Plant species & Concentration* & Reference \\
\hline Clothianidin & Zea mays & $8-102 \mathrm{mg} \mathrm{L}^{-1}$ & $\begin{array}{l}\text { Frommberger et al., } 2011 \\
\text { Tapparo et al., } 2011 \\
\text { Girolami et al., } 2009\end{array}$ \\
\hline Imidacloprid & $\begin{array}{c}\text { Zea mays } \\
\text { Cucumis melo } \\
\text { Agrostis stolonifera }\end{array}$ & $\begin{array}{l}346 \mathrm{mg} \mathrm{L}^{-1} \\
48 \mathrm{mg} \mathrm{L}^{-1} \\
37 \mathrm{mg} \mathrm{L}^{-1}\end{array}$ & $\begin{array}{l}\text { Tapparo et al., } 2011 \\
\text { Girolami et al., } 2009 \\
\text { Hoffmann and Castle, } 2012 \\
\text { Larson et al., } 2015\end{array}$ \\
\hline Thiamethoxam & Zea mays & $12-146 \mathrm{mg} \mathrm{L}^{-1}$ & $\begin{array}{l}\text { Tapparo et al., } 2011 \\
\text { Girolami et al., } 2009\end{array}$ \\
\hline Glyphosate & Agropyron repens & NR & $\begin{array}{l}\text { Coupland and Caseley } \\
\text { (1979) }\end{array}$ \\
\hline Catalase & $\begin{array}{c}\text { Zea mays } \\
\text { Avena sativa }\end{array}$ & $\begin{array}{l}\mathrm{NR} \\
\mathrm{NR}\end{array}$ & $\begin{array}{l}\text { Wilson (1923) } \\
\text { Biles and Abeles (1991) } \\
\text { Komarnytsky et al. (2000) }\end{array}$ \\
\hline Peroxidase & $\begin{array}{c}\text { Cynodon dactylon } \\
\text { Poa pratensis }\end{array}$ & $\begin{array}{l}\mathrm{NR} \\
\mathrm{NR}\end{array}$ & $\begin{array}{l}\text { Wilson (1923) } \\
\text { Biles and Abeles (1991) } \\
\text { Komarnytsky et al. (2000) }\end{array}$ \\
\hline
\end{tabular}

*NR: not reported 


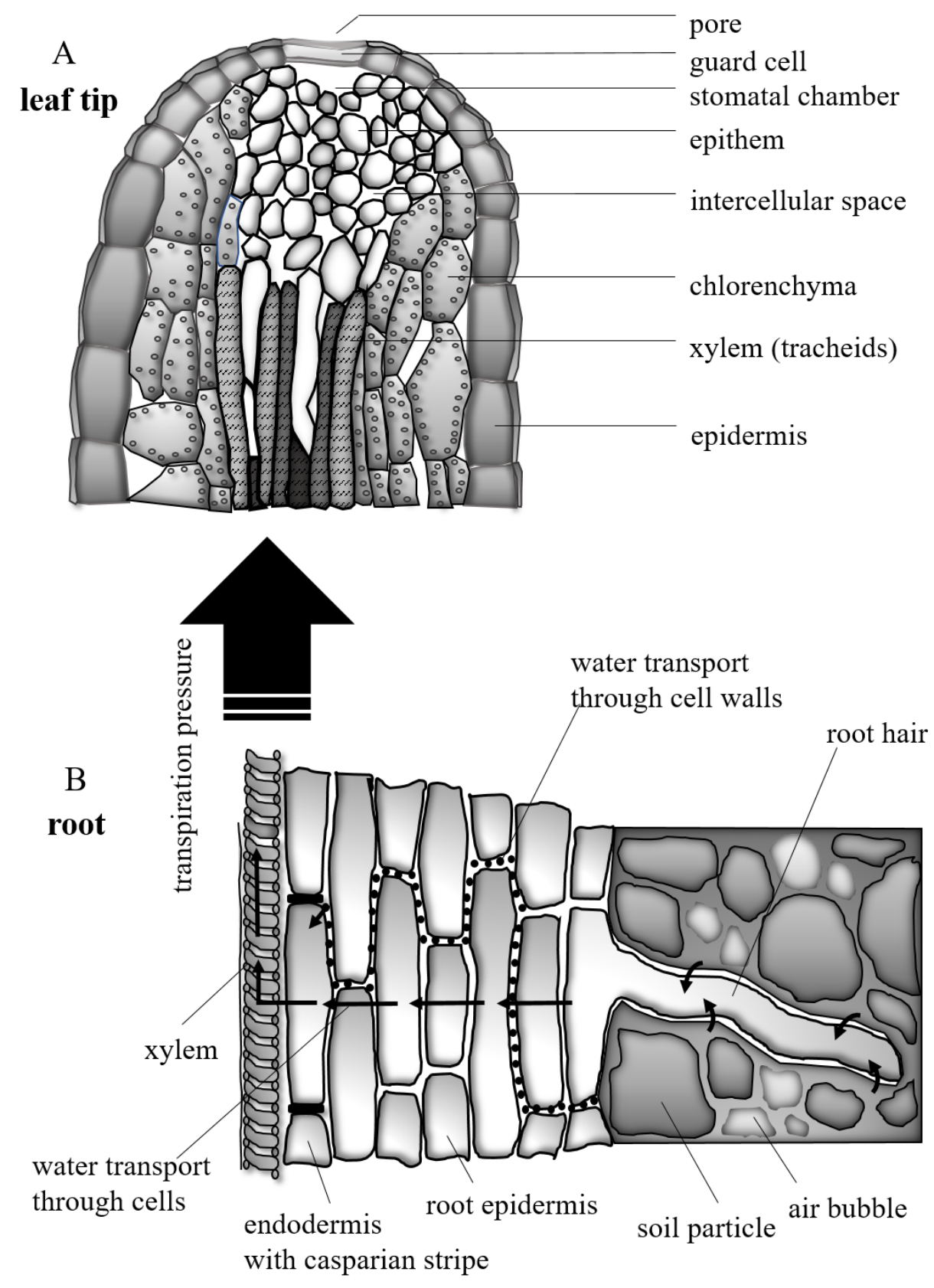

Fig. 1: Schematic drawing of the proposed uptake possibilities of water and dissolved

532 compounds including microcystin-LR via (B) root hair into the root system of plants

533 transporting water through cell walls and cells into the xylem. Arriving at the xylem, the

534 root pressure will facilitate the transport up into stem and leaf. At the (A) leaf tip, the

535 hydathode structure (redrawn from Stevens (1956)) will allow the water and solved 536 compounds to be excreted from the leaf tip as guttation drop. 

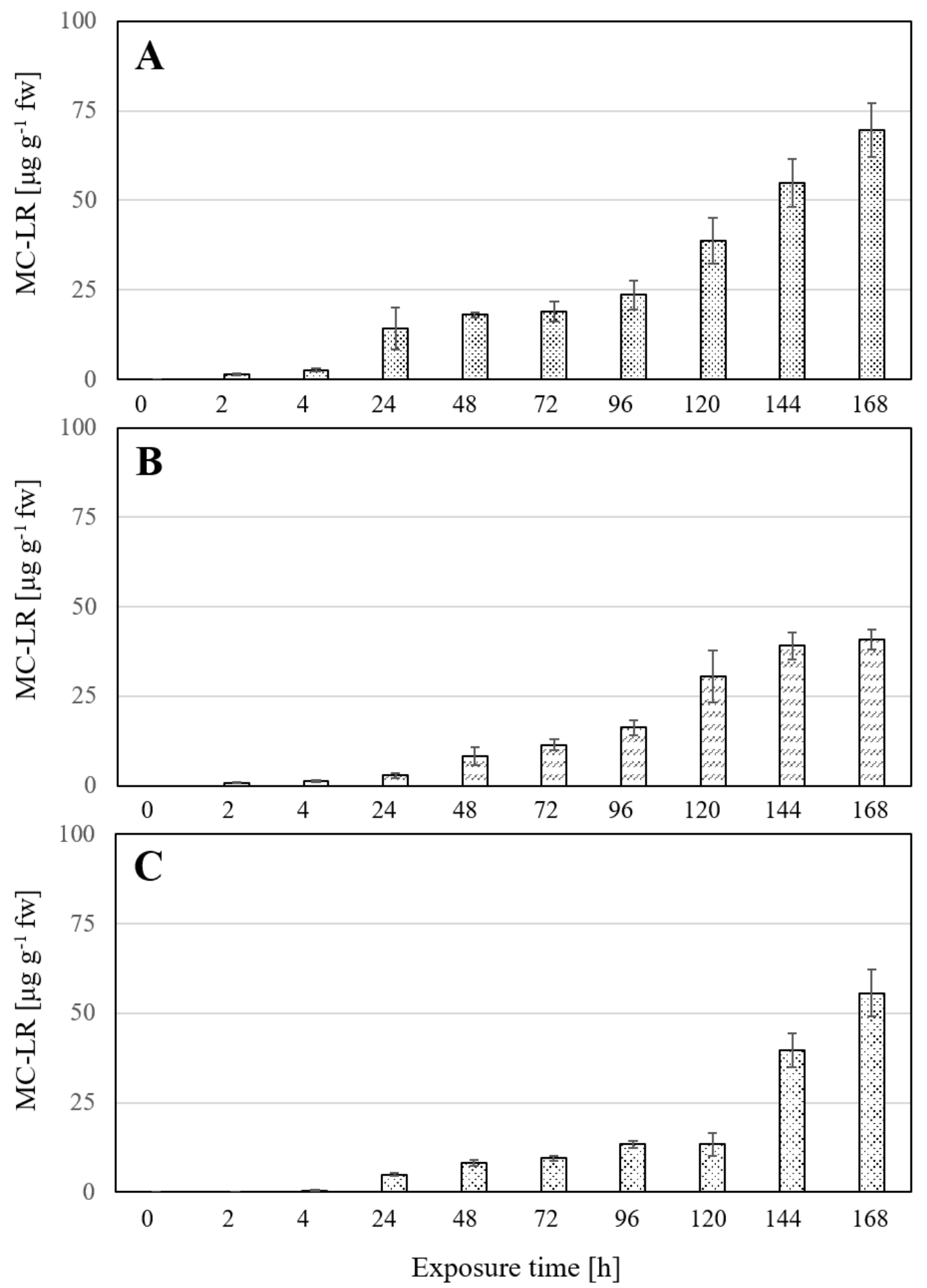

538 Fig. 2: MC-LR concentration detected in (A) the root system (B) the stem, and (C) leaves 539 of the T. aestivum seedlings. Data represent the mean concentration of MC-LR in 540 microgram per gram of plant fresh weight \pm the standard deviation $(n=200)$. 


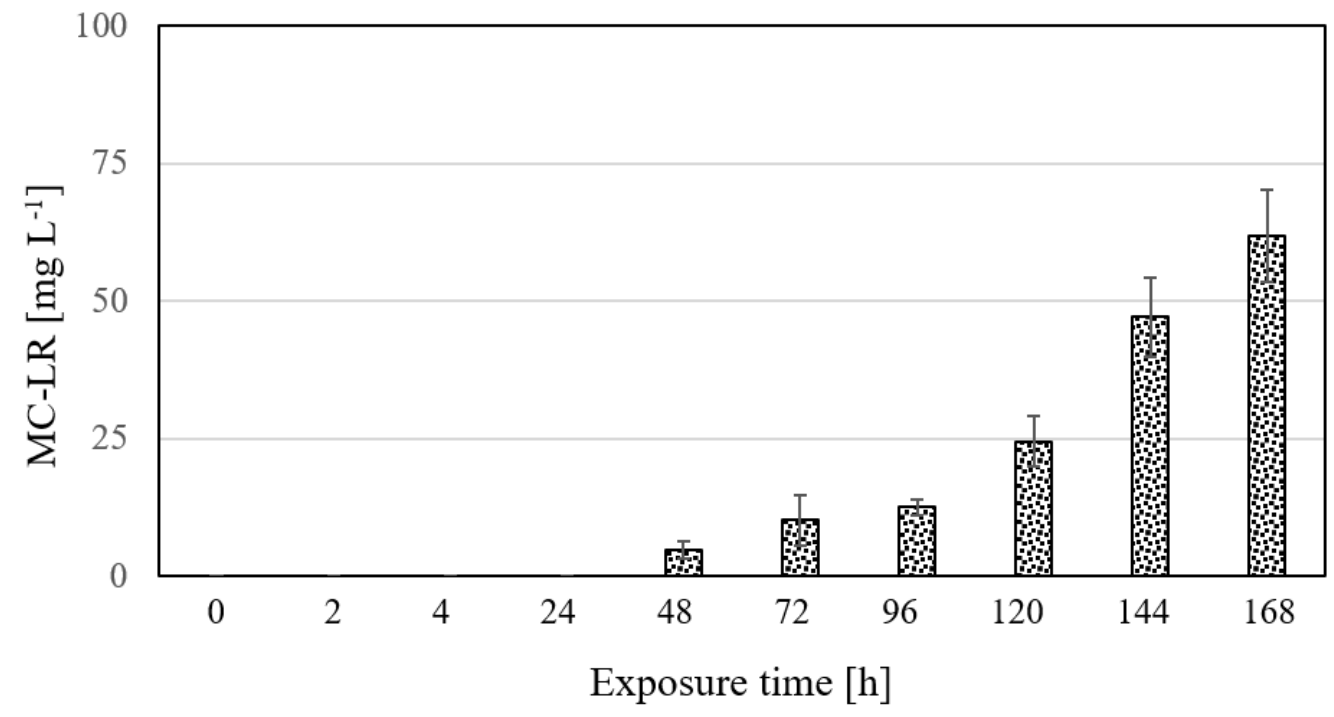

542

543 Fig. 3: MC-LR concentration in the guttation drops of T. aestivum after $48 \mathrm{~h}$ of exposure.

544 Data represent the mean concentration of MC-LR in milligram per litre guttation collected $545 \pm$ the standard deviation $(n=200)$. 


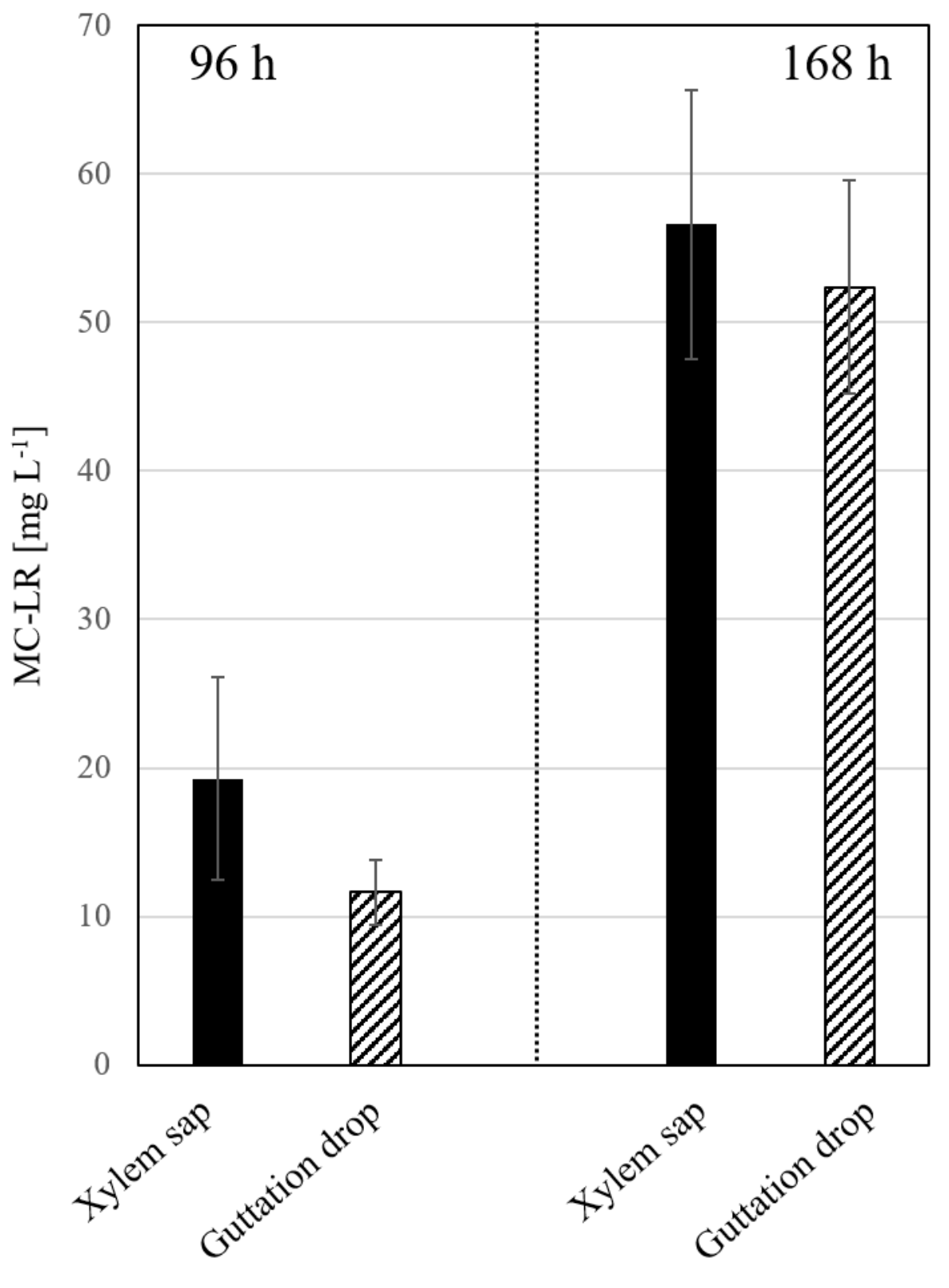

547 Fig. 4: Comparison of MC-LR concentration in xylem sap and guttation drops after $96 \mathrm{~h}$

548 and $168 \mathrm{~h}$ of exposure. Data represent the mean concentration of MC-LR in milligram per

549 litre guttation collected \pm standard deviation $(n=200)$. 